\title{
NON-COMMUNICABLE DISEASE (NCD) - HIGH TIME TO ADDRESS
}

PROF. QUAZI DEEN MOHAMMAD

Principal, Dhaka Medical College
J Dhaka Med Coll. 2011; 20(2) : 95
Bangladesh is a country where there is abundant water, forest, illiteracy, poverty and population. All these are enough for many diseases to make nest, survive and causing out- breaks at times. The most common diseases in this country are related to infection particularly communicable disease and nutrition. In the past infectious and nutritional diseases negotiated many lives and still remaining as a potential threat to lives in vast majority of population. But the havoc caused by infectious and nutritional diseases are now declining. Now we can claim that some of the infectious \& nutritional diseases have been controlled or eradicated from the community. This improvement has been possible because of extensive door to door health care service, adopting prevention strategy and public awareness. With the success in this wing there is emergence of the other wing e.i. noncommunicable disease (NCD). The major NCD includes Hypertension (HTN), Ischemic Heart Disease (IHD), Diabetes Mellitus (DM), stroke and cancer. NCD is now global problem which is affecting many potential lives and causing mortality and morbidity. According to WHO heart attack is the first, cancer is the second and stroke is the third common of death world wide. Every one in 6 six die due to stroke, every eight second one die due to diabetes. This year $29^{\text {th }}$ October has been observed as world stroke day and $14^{\text {th }}$ November was observed as world diabetes day. The main slogan was prevention is better than cure.

In Bangladesh as the elderly segment of population is increasing so the NCD is also increasing. All of NCD are quite prevalent to a large extent in this country. The prevalence of stroke in Bangladesh is 350-400 / 100000, $6-10 \%$ of the population has DM, $11 \%$ of population has HTN, 3-5\% of population has IHD and the incidence of cancer is 1 in 181 (according to respective society report). In the context of socio-economic status of Bangladesh every disease is extremely important and needs to address immediately.

In the meantime Govt. of Bangladesh \& WHO has felt the significance of NCD. So they have taken necessary steps to find out the status of the disease $\&$ how to get cure $\&$ prevention. By the time different medical professional bodies are now well aware and in agony. They particularly the related society of subspecialties are taking different programme like symposium, seminar for the general practitioner, mass people and patients to disseminate the importance of awareness as a part to prevent NCD.

There are many known factors, related to NCD like, diet, obesity, smoking, life style, alcohol, hyperlipidaemia etc. Most of them are either controllable or preventable. In that context most of the NCD can be prevented. The burden of treatment cost is more than the prevention approach, so prevention is always advisable and preferable. This can only be possible if the community is awarded through mass awareness programme done by professional bodies. By the act of all hopefully non communicable disease (NCD) will also be in grip here in Bangladesh in near future. 